\title{
Caracterização de hemoglobina N-Baltimore em doador de sangue de São José do Rio Preto, SP
}

\author{
Hemoglobin N-Baltimore caracterization in a blood donor of São J osé do Rio Preto, SP, Brazil
}

\author{
Claudia Regina Bonini-Domingos ${ }^{1}$ \\ Eduardo Lani Volpi da Silveira² \\ Lígia Márcia Silveira Viana-Baracioli ${ }^{3}$
}

Andreia Averci Canali ${ }^{4}$

\section{unitermos resumo}

As alterações que envolvem as globinas devem-se a modificações em genes responsáveis pela seqüência e estrutura das cadeias polipeptídicas, bem como aos genes reguladores da síntese destas cadeias. Hemoglobinas variantes apresentam estrutura química diferente da hemoglobina normal correspondente, resultante de mutações em uma ou mais bases nitrogenadas, ocasionando a troca de aminoácidos nas globinas alfa, beta, delta ou gama. A hemoglobina N-Baltimore é uma variante de globina beta, com substituição da lisina, na posição 95, por ácido glutâmico, apresentando mobilidade eletroforética mais rápida que a hemoglobina $\mathrm{A} \mathrm{em} \mathrm{pH}$ alcalino. Nas análises eletroforéticas em $\mathrm{pH}$ alcalino realizadas em doadores de sangue do Hemocentro de São José do Rio Preto (SP) identificamos a presença de portador de hemoglobina rápida em heterozigose, posteriormente confirmada por focalização isoelétrica e cromatografia líquida de alta pressão (HPLC). Os estudos de hemoglobinas anormais em doadores de sangue permitem a identificação de variantes raras e possibilitam o aconselhamento genético adequado a cada caso com estudo familial.

\section{abstract}

The alterations that involve globin chains are due to modifications in genes responsible for the sequence and structures of each polypeptide chain, as well as to regulator genes of the synthesis.

Variant hemoglobin presents different chemical structure from the corresponding normal hemoglobin, resultant of mutations in one or more bases, causing change of amino acids in the alpha, beta, delta or gamma chain. The hemoglobin $\mathrm{N}$ is a beta globin variant, with substitution of lisina, in the position 95, for a glutamic acid, promoting electrophoretic mobility faster than the hemoglobin A in alkaline pH. In electrophoretical analysis of blood donor from São José do Rio

Preto, SP, a carrier of hemoglobin N was identified in heterozygous, confirmed by isoelectric focusing and HPLC. The hemoglobin studies in blood donors permit the identification of rare variants and facilitate the genetic counseling and familial study.

key words

Hemoglobin $\mathrm{N}$

Globin chain

Abnormal hemoglobins 


\section{Introdução}

As alterações que envolvem as globinas devem-se a modificações em genes responsáveis pela seqüência e estrutura das cadeias polipeptídicas, bem como a genes reguladores da síntese destas cadeias (1).

A hemoglobina $\mathrm{N}(\mathrm{Hb} \mathrm{N})$ é uma variante que não acarreta alteração fisiológica em heterozigose, apesar de apresentar uma estrutura química diferente da hemoglobina normal, sendo seu portador considerado assintomático. É resultante de uma mutação na posição 95 da globina beta, onde ocorreu uma substituição do aminoácido lisina por ácido glutâmico (2). Esta troca de um aminoácido positivo por um outro negativo promove uma mobilidade eletroforética da $\mathrm{Hb} \mathrm{N}$ mais rápida que da hemoglobina $\mathrm{A}$ $(\mathrm{Hb} A)$ em pH alcalino. Por não apresentar sintomas clínicos, os portadores desta hemoglobina são detectados apenas por estudos populacionais ou quando a $\mathrm{Hb} \mathrm{N}$ estiver associada a formas talassêmicas ou a outras variantes de hemoglobina (3).

Os procedimentos eletroforéticos utilizados para caracterização da $\mathrm{Hb} \mathrm{S}$ em bancos de sangue têm favorecido o diagnóstico laboratorial de outras variantes de hemoglobina de rara freqüência, como a hemoglobina $\mathrm{N}$. $\mathrm{O}$ diagnóstico das alterações de hemoglobinas pode ser facilitado através da constante atualização das metodologias aplicadas na caracterização destes mutantes e treinamento de pessoal para seu correto diagnóstico laboratorial (4-6). A caracterização dos mutantes de hemoglobina favorece o conhecimento destas alterações na população brasileira e permite a adequada orientação aos portadores.

\section{Materiais e métodos}

Amostras de sangue foram colhidas, com EDTA como anticoagulante, de doador de sangue após consentimento informado.

Os procedimentos de análise aplicados incluem testes de triagem e confirmações para diagnóstico de hemoglobinopatias, conforme listado a seguir:

- para triagem - resistência globular osmótica em solução de $\mathrm{NaCl}$ a $0,36 \%$ (7), análise da morfologia eritrocitária (4), eletroforese em pH alcalino (8);

- para confirmação - eletroforese em pH ácido (9), isoeletrofocalização (IEF), eletroforese de cadeias polipeptídicas (10), HPLC em sistema Variant da BioRad; análise molecular por PCR-ASO (Linha mDx - Bio-
Rad). As metodologias de HPLC e PCR-ASO seguiram os protocolos estabelecidos pelos fabricantes.

\section{Resultados}

Através de análises eletroforéticas realizadas como rotina em doadores de sangue do Hemocentro de São José do Rio Preto (SP) foi identificado um candidato à doação, adulto, negróide, do sexo masculino, portador de uma hemoglobina rápida. Após consentimento informado, nova amostra de sangue foi colhida através de punção venosa, acondicionada em tubos contendo EDTA a 5\% como anticoagulante, e posteriormente encaminhada, sob refrigeração, ao Laboratório de Hemoglobinas e Genética das Doenças Hematológicas da Unesp para caracterização da fração anômala.

Ao chegar ao laboratório a amostra foi codificada para preservar a identidade do doador. Para triagem de hemoglobinas anormais utilizaram-se os testes previamente descritos, nos quais observou-se negatividade no teste de resistência globular osmótica em $\mathrm{NaCl}$ a $0,36 \%$, o que é considerado normal neste procedimento de triagem de hemoglobinopatias, e a análise da morfologia eritrocitária apresentou-se dentro dos parâmetros de normalidade. $\mathrm{Na}$ eletroforese em $\mathrm{pH}$ alcalino, a amostra apresentou padrão de migração com banda de $\mathrm{Hb} \mathrm{A}$ e fração mais rápida que a $\mathrm{Hb} \mathrm{A}$, tanto em acetato de celulose quanto em gel de agarose. A Figura ilustra a migração eletroforética da amostra com suspeita de hemoglobina anormal em acetato de celulose (A) e em gel de agarose (B), em pH alcalino, evidenciando a migração mais rápida da fração quando comparada com as outras amostras. Em gel de agarose e pH alcalino, para melhor visualização da banda anormal, realizou-se o procedimento eletroforético com amostras hemolisadas com saponina a 1\% e com clorofórmio, sendo que neste último a visualização foi muito mais clara. $\mathrm{O}$ perfil eletroforético apresentado sugeriu heterozigose para hemoglobina $\mathrm{N}$ através da comparação da migração com mapas específicos (3).

Devido ao aparecimento da fração anormal de hemoglobinas nos procedimentos analíticos de triagem, a amostra foi submetida aos métodos de confirmação: eletroforese em pH ácido, eletroforese de cadeias polipeptídicas, focalização isoelétrica (IEF) no equipamento PhastSystems, Pharmacia e cromatografia líquida de alta pressão (HPLC) com equipamento Variant da Bio-Rad e kit de análise para betatalassemia menor. Na eletroforese em gel de agarose, pH ácido, a amostra não apresentou diferença quanto à migração em relação à $\mathrm{Hb} \mathrm{A}$. Por focalização 


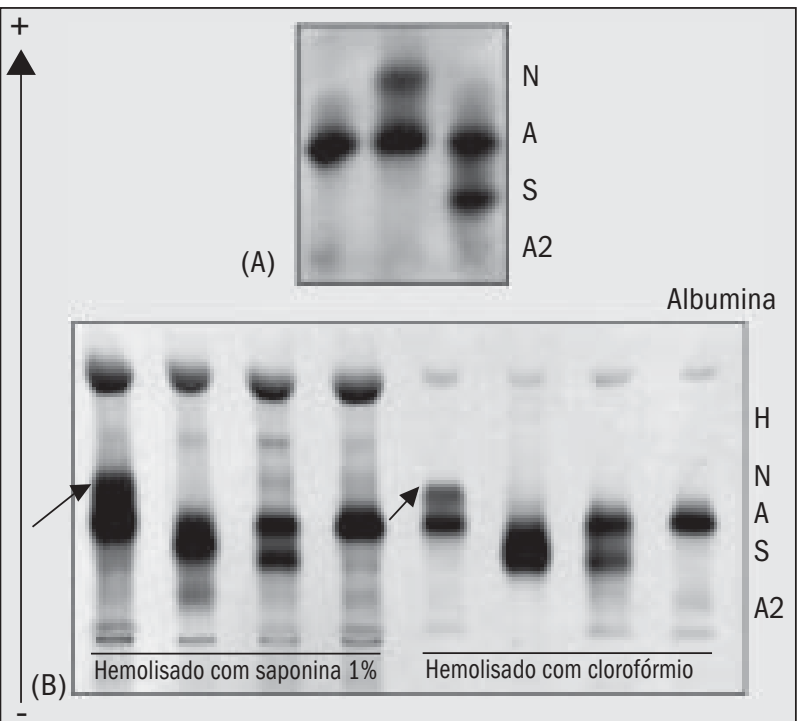

Figura - Migração eletroforética de amostras de sangue em acetato de celulose (A) e gel de agarose Celm (B) em pH alcalino, evidenciando a presença de hemoglobina $\mathrm{N}$ em heterozigose (setas)

isoelétrica, onde as hemoglobinas são separadas pelos seus pontos isoelétricos, a amostra apresentou padrão compatível com $\mathrm{Hb}$ AN, posteriormente caracterizado como mutante de cadeia beta por eletroforese de cadeias globínicas.

No cromatograma obtido por HPLC, cuja metodologia permite a separação das frações de hemoglobinas por eluição em coluna de troca iônica com a injeção de tampões em sistema de alta pressão, observou-se fração anormal de $46,5 \%$ com tempo de retenção de 1,59 e perfil sugestivo de $\mathrm{Hb} \mathrm{N}$-Baltimore em heterozigose. A quantificação das hemoglobinas $A_{2}$ e fetal, por esta metodologia, mostrou valores de $2,5 \%$ e $3 \%$, respectivamente. Por desnaturação alcalina (3) a $\mathrm{Hb} \mathrm{F}$ apresentou valores de $1,8 \%$, discretamente acima do valor de referência normal de 0 a $1 \%$. $\mathrm{O}$ valor aumentado de $\mathrm{Hb}$ fetal sugeriu interação com talassemias. Esta suspeita foi afastada rastreando-se os 16 mutantes mais freqüentes para talassemias do tipo beta e a deleção alfa 3,7 para alfatalassemia, por metodologia de hibridização com sonda oligonucleotídica específica (ASO), pelo kit de diagnóstico $\mathrm{mDx}$ da Bio-Rad. A quantidade de $\mathrm{Hb}$ fetal observada por HLPC pode ser devida à presença de subfrações da fração anormal majoritária, identificada na mesma janela de $\mathrm{Hb}$ fetal pelo programa de diagnóstico aplicado.
A Hb N-Baltimore, também chamada Hb Hopkins-I, Jenkis, N-Memphis e Kenwood, é uma mutação com troca de base no gene da betaglobina [ $\beta 95(\mathrm{FG} 2) \mathrm{AAG}>\mathrm{GAG}$ ] e substituição do aminoácido lisina por glutamato na cadeia polipeptídica. Possui afinidade com o oxigênio e estabilidade normais, e foi primeiramente descrita em famílias negras do sudoeste americano (11).

\section{Discussão}

Os portadores de hemoglobinas anormais, em especial de talassemias, apresentam anisopoiquilocitose com prevalência de microcitose e hipocromia no estudo de morfologia eritrocitária. Este procedimento laboratorial, aliado à resistência globular osmótica em $\mathrm{NaCl}$ a $0,36 \%$ e à eletroforese alcalina, fornece subsídios para uma boa triagem de amostras de sangue com suspeita de hemoglobinopatias $(3,4,6)$.

Diferentes mobilidades eletroforéticas das hemoglobinas anormais devem-se à alteração de carga elétrica, causada por substituições de aminoácidos, nas cadeias formadoras das moléculas. As hemoglobinas anormais que se originam de mutações onde não ocorre mudança de carga elétrica migram na posição da hemoglobina A em eletroforese alcalina (6). No entanto a co-migração de hemoglobinas anormais com ponto isoelétrico semelhante, em pH alcalino, e o componente genético da população brasileira, intensamente miscigenada, evidenciam a necessidade de testes complementares para a caracterização das anormalidades de hemoglobinas e seus respectivos mutantes.

Através de análises eletroforéticas realizadas em doadores de sangue do Hemocentro de São José do Rio Preto (SP) foi identificado um portador de hemoglobina rápida, cuja alteração foi posteriormente confirmada por eletroforese de cadeias polipeptídicas, IEF e HPLC como heterozigoto para hemoglobina N-Baltimore. A associação dos procedimentos eletroforéticos, cromatográficos e a comparação com os relatos da literatura permitiram a caracterização da variante de hemoglobina, possibilitando abordagem genético-educacional efetiva e adequada ao portador e seus familiares, contribuindo para o conhecimento da prevalência destes mutantes na população brasileira.

\section{Referências}

1.W eatherall, D.J.The thalassaemias. Brit. M ed.J., 314:1675-8,1997.

2. Honig, G.R.; A dams III, J.G. Human hemoglobin genetics. N ew York: Springer, 1986.
3. N aoum, P.C . Eletroforese: técnicas e diagnósticos. 2. ed. São Paulo: Editora Santos, 1999.

4. Bonini-D omingos, C .R. Prevenção das hemo glo bino patias no 
Brasil: diversidade genética e meto dologia laboratorial. São José do Rio Preto, 1993. Tese (Doutorado em Ciências Biológicas). Instituto de Biociências, Letras e Ciências Exatas, Universidade Estadual Paulista.

5. Prudêncio, B.C .A.B.D etecção de hemoglobina S em doadores de sangue: um estudo comparativo entre os métodos tubogel e solubilidade. São José do Rio Preto, 1998.Tese (Mestrado em Ciências da Saúde). Faculdade de Medicina de São José do Rio Preto-SP.

6. Guideline. The laboratory diagnosis of haemoglobinopathies. British. J. H aematol., 101: 783-92, 1998.
7. Silvestroni, E. \& Bianco, I. Screening for microcytemia in Italy: analysis of data collected in the past 30 years. Am. J. Hum. Genet., 27: 198-212, 1975.

8. Marengo-Rowe, A.J. Rapid electrophoresis and quantification of hemoglobin on cellulose acetate.J.Clin. Pathol.,18:790-2,1965.

9.Vella, F. A cid agar electrophoresis of human hemoglobin. Am. J. Clin. Pathol., 49(3): 440-2, 1968.

10. Schmidt, R.M. \& Brossio us, E.M. Basic laboratory methods of hemoglobinopathy detection.G eorgia:H ew Publication, 1976.

11. Huisman, T.H J. A Syllabus of human hemoglobin variants 1996. http://globin.cse.psu.edu/globin. 